\title{
Comparative Studies on the DNA-binding Properties of Linear and Angular Dibenzoquinolizinium Ions
}

Heiko Ihmels, ${ }^{*}$ Daniela Otto, Francesco Dall'Acqua, Anita Faccio, Stefano Moro and Giampietro Viola

\section{Supporting Information}

\section{Content}

General

Experimental Section 3

Materials and Methods 3

NMR Spectra

${ }^{1} \mathrm{H}-\mathrm{NMR}$ spectrum of $\mathbf{a h h}-(\mathbf{5 a})_{2}$ 4

ROESY-NMR spectrum of $\mathbf{a h h}-(\mathbf{5 a})_{2}$ 6

DNA-Titration Experiments

Spectrophotometric titration of (poly $[\mathrm{dG}-\mathrm{dC}])_{2}$ to $\mathbf{5 a}\left(\mathbf{B F}_{4}\right)$ and $\mathbf{6}$ 8

Spectrophotometric titration of (poly[dA-dT] $)_{2}$ to $\mathbf{5 a}\left(\mathbf{B F}_{\mathbf{4}}\right)$ and $\mathbf{6} \quad 9$

Scatchard Plots of the spectrophotometric titration of ct DNA to $\mathbf{5 a}\left(\mathbf{B F}_{\mathbf{4}}\right)$ and $\mathbf{6}$ 10

Thermal Denaturation Studies

Melting profiles of $(\text { poly }[\mathrm{dA}-\mathrm{dT}])_{2}$ in the presence of $\mathbf{5} \mathbf{a}\left(\mathbf{B F}_{\mathbf{4}}\right)$ at different $\left[\mathrm{Na}^{+}\right]$concentrations 10

Melting profiles of (poly $[\mathrm{dA}-\mathrm{dT}])_{2}$ and ct DNA in the presence of 9 11

Melting profiles of poly[dA]-poly $[\mathrm{dT}]_{2}$ in the presence of 9 11

Competition Dialysis Studies

Competition Dialysis data for 9 12

Degradation Studies

Temperature dependent degradation of $\mathbf{5} \mathbf{a}\left(\mathbf{B F}_{\mathbf{4}}\right)$ 12

Time dependent spectrophotometric investigations on the stability of $\mathbf{5 a}(\mathbf{B r})$ 13

$\mathrm{UV} / \mathrm{Vis}$ absorption spectra

UV/Vis absorption spectra of 1-methoxynaphthalene, $\mathbf{a h h}-(\mathbf{5 a})_{2}$ and $\mathbf{5 a}(\mathbf{B r})$ 13

UV/Vis absorption spectra of $\mathbf{5 a}(\mathbf{B r})$ (black line) irradiated through a cut-off-filter 13

Molecular Modelling

Optimized geometries of the intercalation complexes of $\mathbf{5 a}$ and $\mathbf{6}$ with ds DNA 14

References 14 


\section{Experimental Section}

Materials and Methods. Dibenzo $[a, f]$ quinolizinium $(6)^{1}$ and benzo $[b]$ quinolizinium $(\mathbf{9})^{2}$ were prepared according to literature procedures. All solvents and reagents were purchased from commercial sources and used without further purification. Only deionised ultrapure

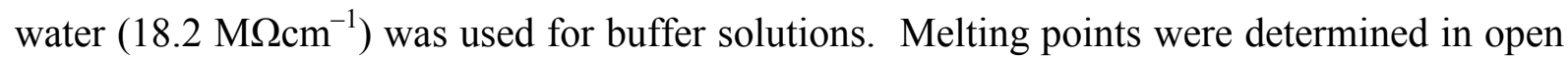
capillary tubes and are uncorrected. ${ }^{1} \mathrm{H}$ and ${ }^{13} \mathrm{C}$ spectra were obtained on $200 \mathrm{MHz}, 400 \mathrm{MHz}$ and $600 \mathrm{MHz}$ NMR spectrometers. Chemical shifts are given as $\delta$ values (internal standard TMS). Mass spectra were obtained by ESI-MS techniques.

Nucleic Acids. Calf thymus DNA (type I, Highly polimerized sodium salt) and micrococcus luteus DNA (type XI, highly polimerized) as well as the polynucleotides poly[dA-dT]-poly[dA-dT], poly[dG-C]-poly[dG-dC] and poly[dA]-poly[dT] and the homopolymer poly[dT] were purchased from commercial sources and used without further purification. Triplex poly[dA]-poly[dT $]_{2}$ was prepared by mixing equimolar amounts of poly[dA]-poly[dT] and poly[dT], dissolved each in BPES buffer, heating to $90{ }^{\circ} \mathrm{C}$ and slow cooling to $4{ }^{\circ} \mathrm{C}$. The concentrations of nucleic acid samples were determined by UV absorbance measurements using the following extinction coefficients $\left(\mathrm{cm}^{-1} \mathrm{M}^{-1}\right.$ for nucleic bases, base pairs (bp) or base triplets (bt), respectively): ct DNA and micrococcus luteus DNA, $\quad \lambda_{260}=12824 \mathrm{~cm}^{-1}(\mathrm{bp}), \quad \lambda_{260}=6600 \mathrm{~cm}^{-1} \quad$ (bases); poly[dA-dT]-poly[dA-dT], $\lambda_{262}=13200 \quad \mathrm{~cm}^{-1}$ (bp), $\lambda_{260}=6600 \quad \mathrm{~cm}^{-1} \quad$ (bases), poly[dG-dC]-poly[dG-dC] $\lambda_{254}=$ $16800 \mathrm{~cm}^{-1}$ (bp), $\lambda_{254}=8400 \mathrm{~cm}^{-1}$ (bases); poly[dA]-poly[dT $\quad \lambda_{260}=12000 \mathrm{~cm}^{-1}$ (bp); poly $[\mathrm{dT}] \lambda_{264}=8520 \mathrm{~cm}^{-1}$ (bases); poly[dA]-poly $[\mathrm{dT}]_{2}, \lambda_{260}=17200 \mathrm{~cm}^{-1}$ (bt). 

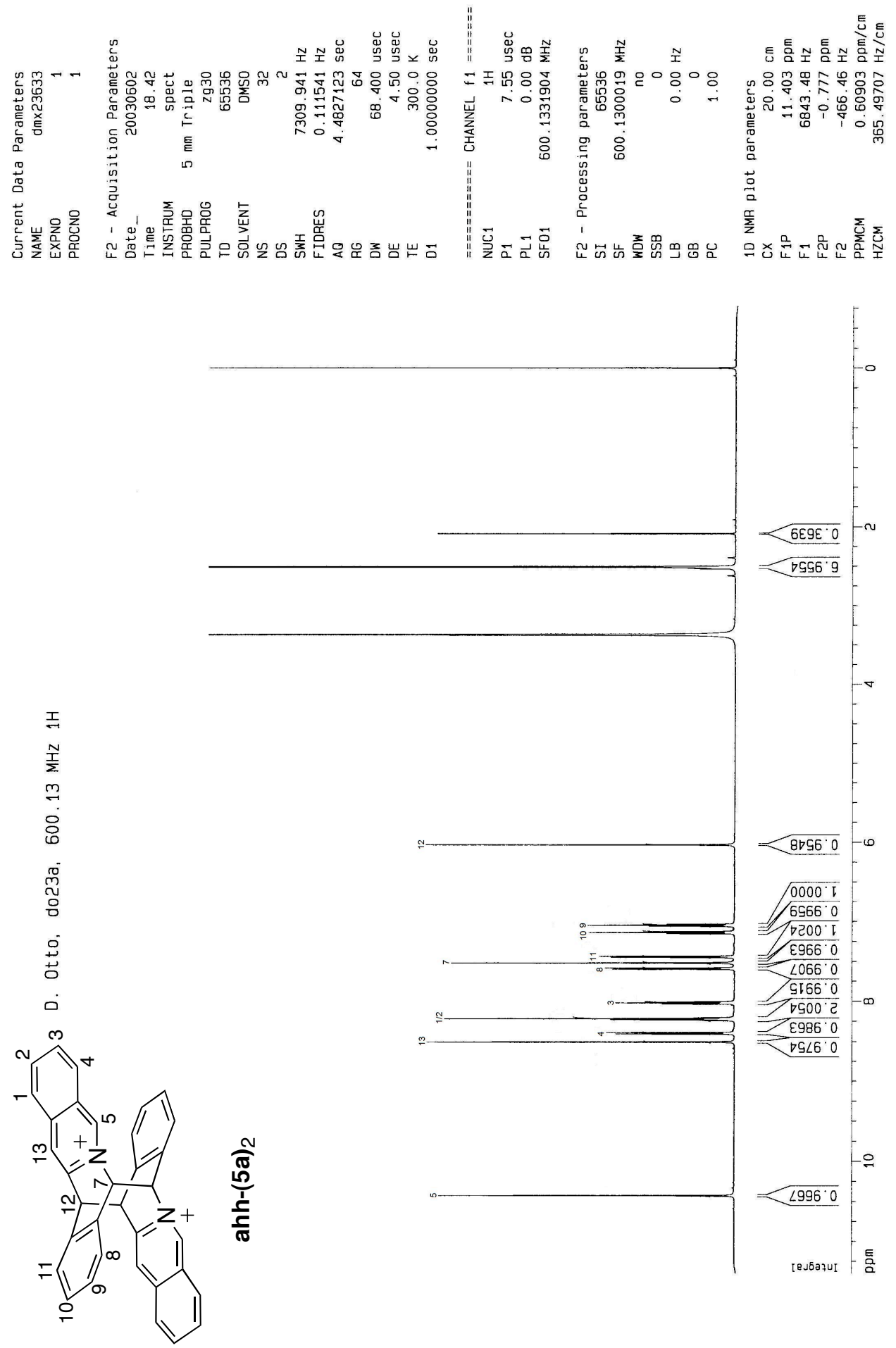

Figure S1. ${ }^{1} \mathrm{H}-\mathrm{NMR}$ spectrum of ahh-(5a) $)_{2}$ in $d_{6}$-DMSO (additional peaks: $0=$ TMS; $2.1=$ $\mathrm{CH}_{3} \mathrm{CN} ; 2.5=$ DMSO, $3.3=\mathrm{H}_{2} \mathrm{O}$. 

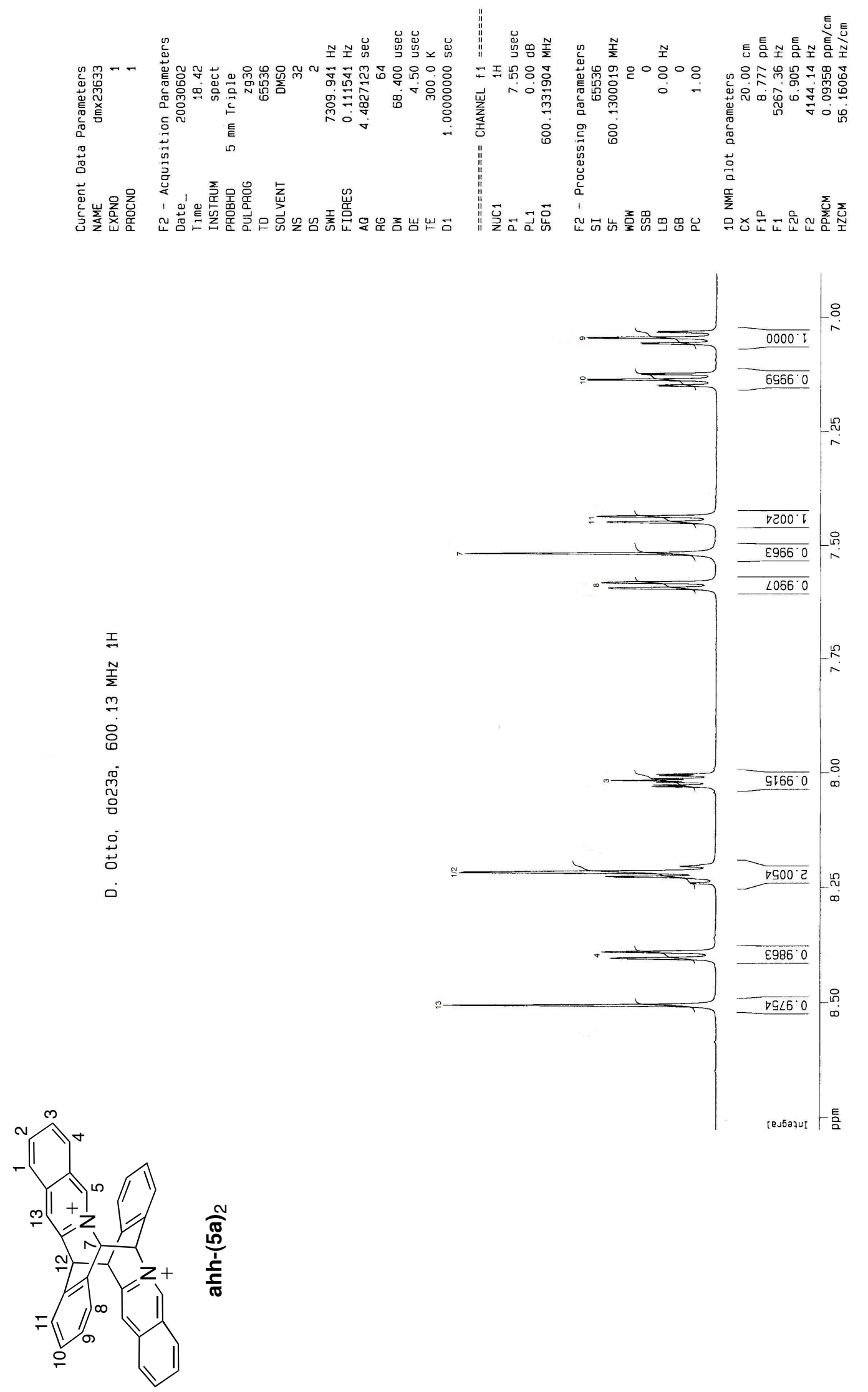

Figure S2. ${ }^{1} \mathrm{H}-\mathrm{NMR}$ spectrum of ahh-(5a) $)_{2}$ in $d_{6}$-DMSO. 

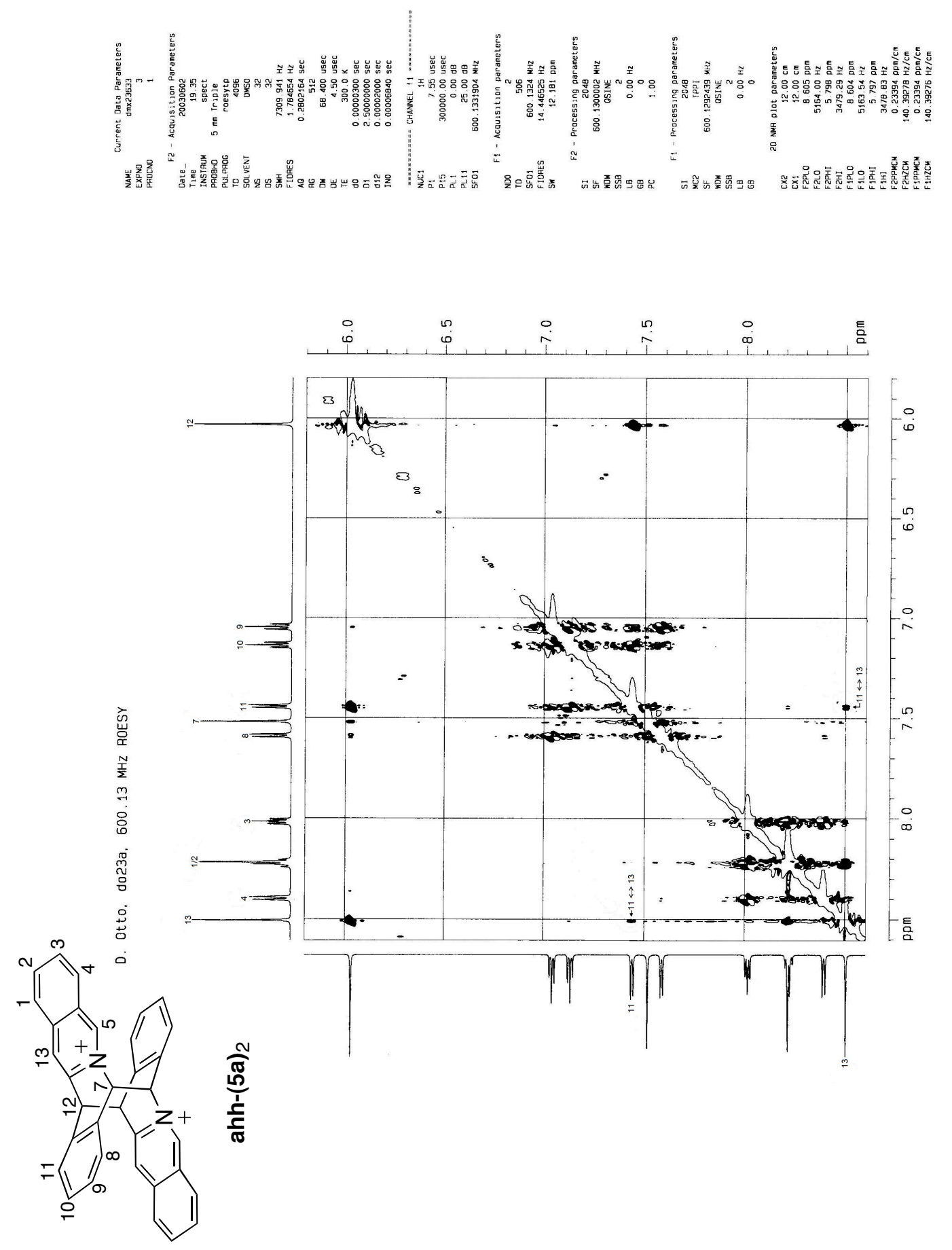

Figure S3. ROESY-NMR spectrum of ahh-(5a) $)_{2}$ in $d_{6}$-DMSO; crosspeaks due to NOE between $11-\mathrm{H}$ and 13 '-H are indicated in the spectrum. 

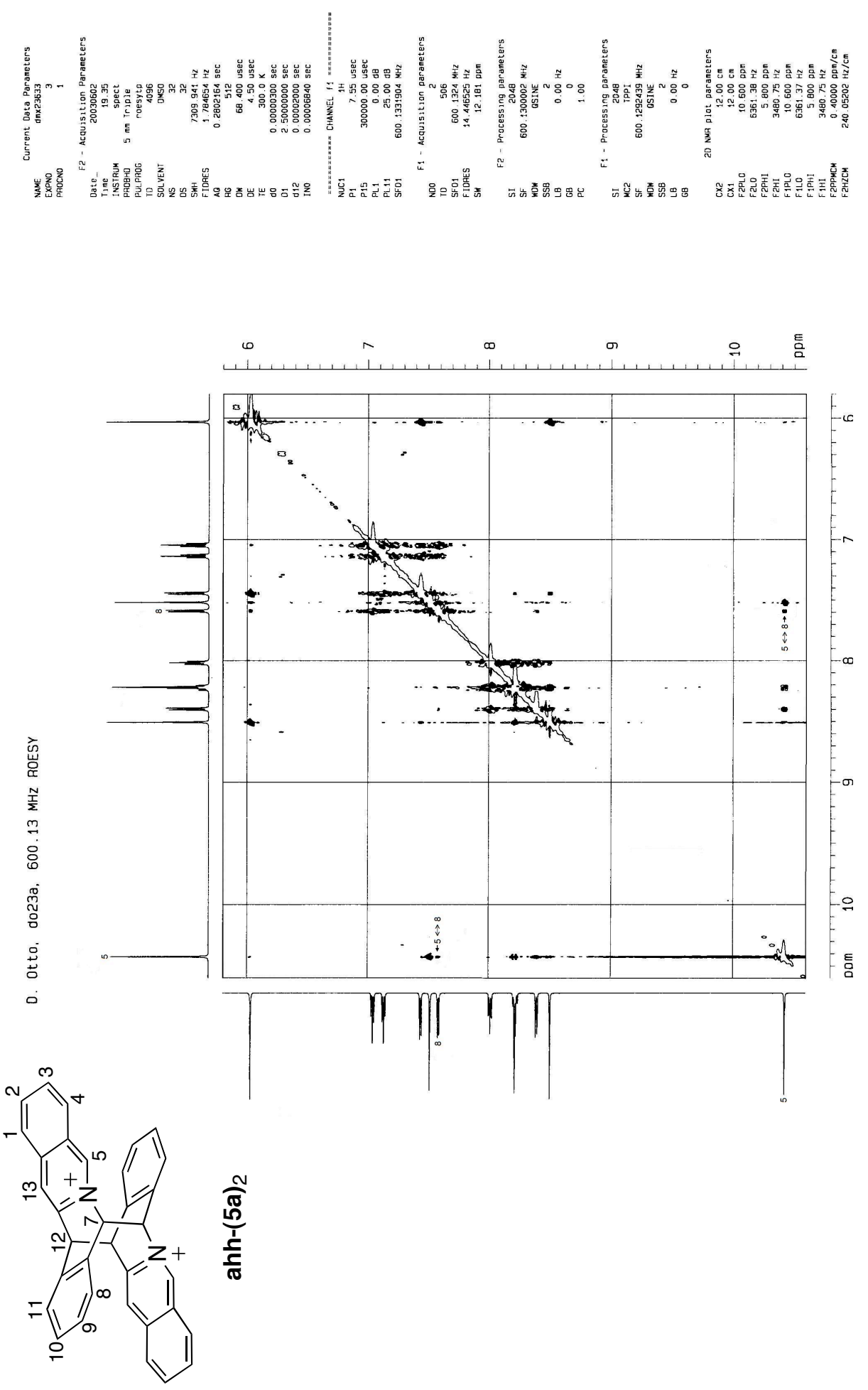

Figure S4. ROESY-NMR spectrum of ahh-(5a) $)_{2}$ in $d_{6}$-DMSO; crosspeaks due to NOE between $5-\mathrm{H}$ and $8^{\prime}-\mathrm{H}$ are indicated in the spectrum 

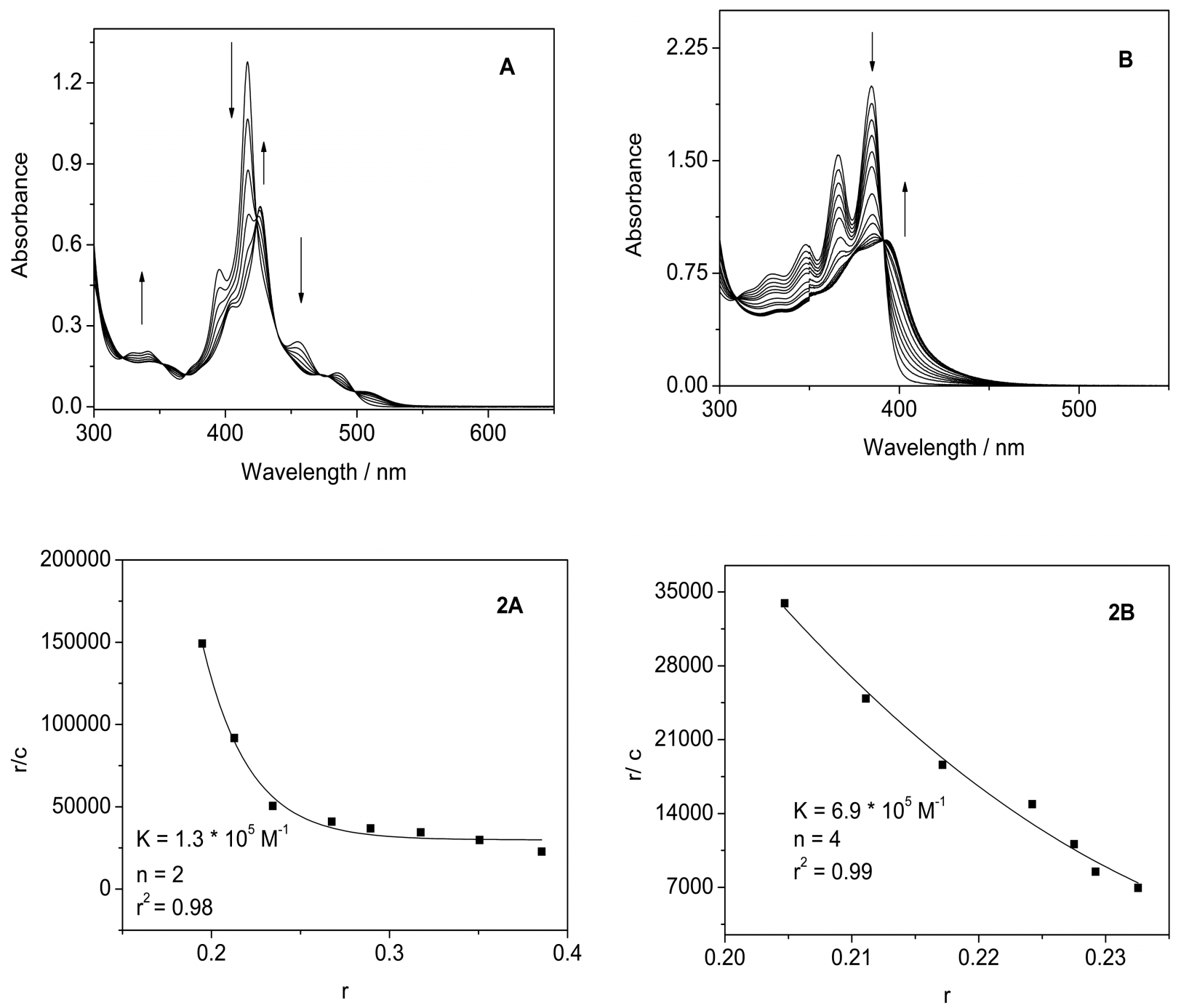

Figure S5. Spectrophotometric titration of poly[dG-dC]-poly[dG-dC] to dibenzoquinolizinium derivatives $\left[\mathbf{5 a}\left(\mathbf{B F}_{4}\right)\right](\mathrm{A})$ and $\mathbf{6}(\mathrm{B})\left(c=10^{-4} \mathrm{M}\right)$ in phosphate buffer (10 mM, pH 7.0, $\left.T=25^{\circ} \mathrm{C}\right)$. 

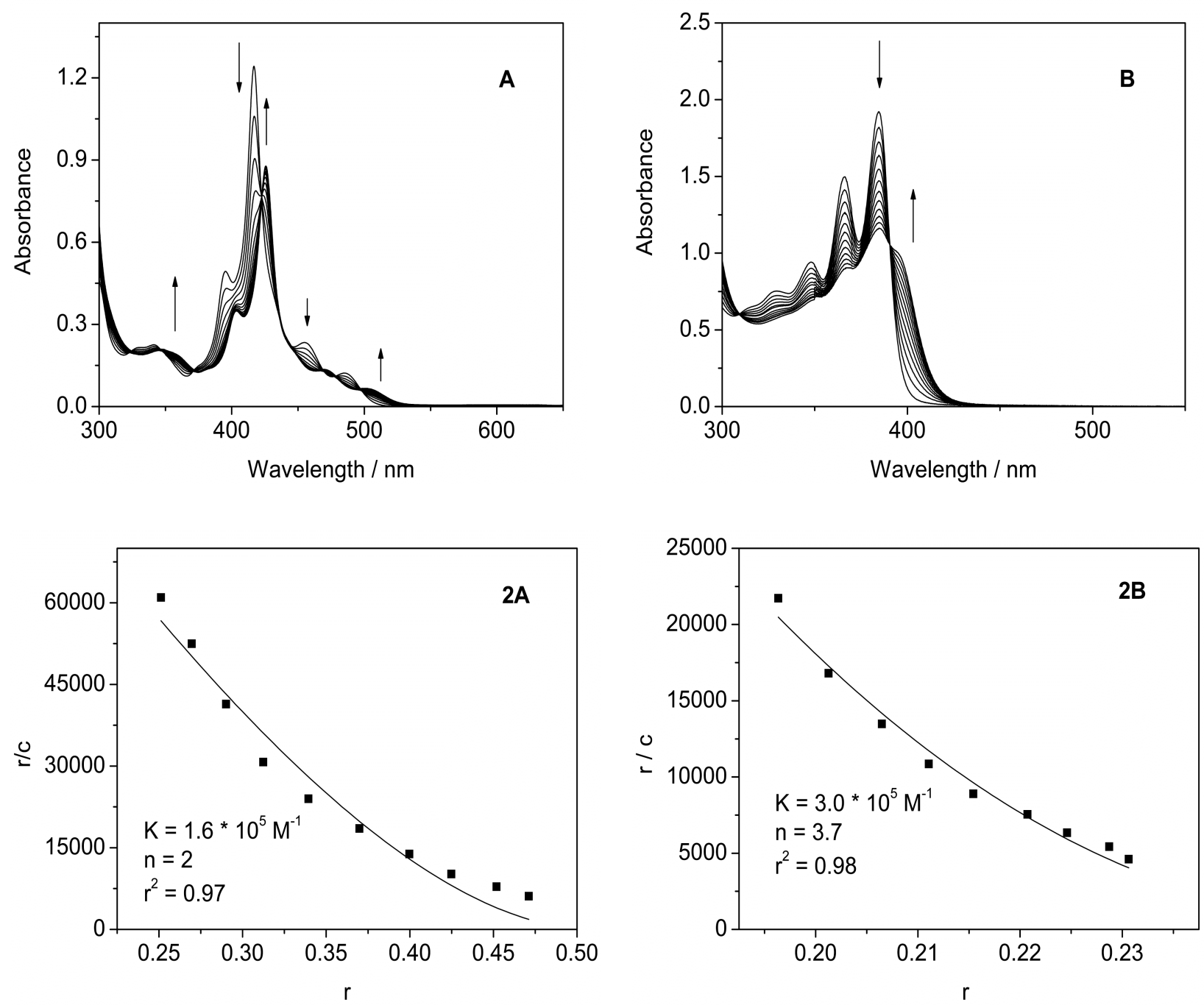

Figure S6. Spectrophotometric titration of poly[dA-dT]-poly[dA-dT] to dibenzoquinolizinium ions $\left[\mathbf{5 a}\left(\mathbf{B F}_{4}\right)\right](\mathrm{A})$ and $\mathbf{6}(\mathrm{B})\left(c=10^{-4} \mathrm{M}\right)$ in phosphate buffer $(10 \mathrm{mM}, \mathrm{pH} 7.0$, $\left.T=25^{\circ} \mathrm{C}\right)$. 

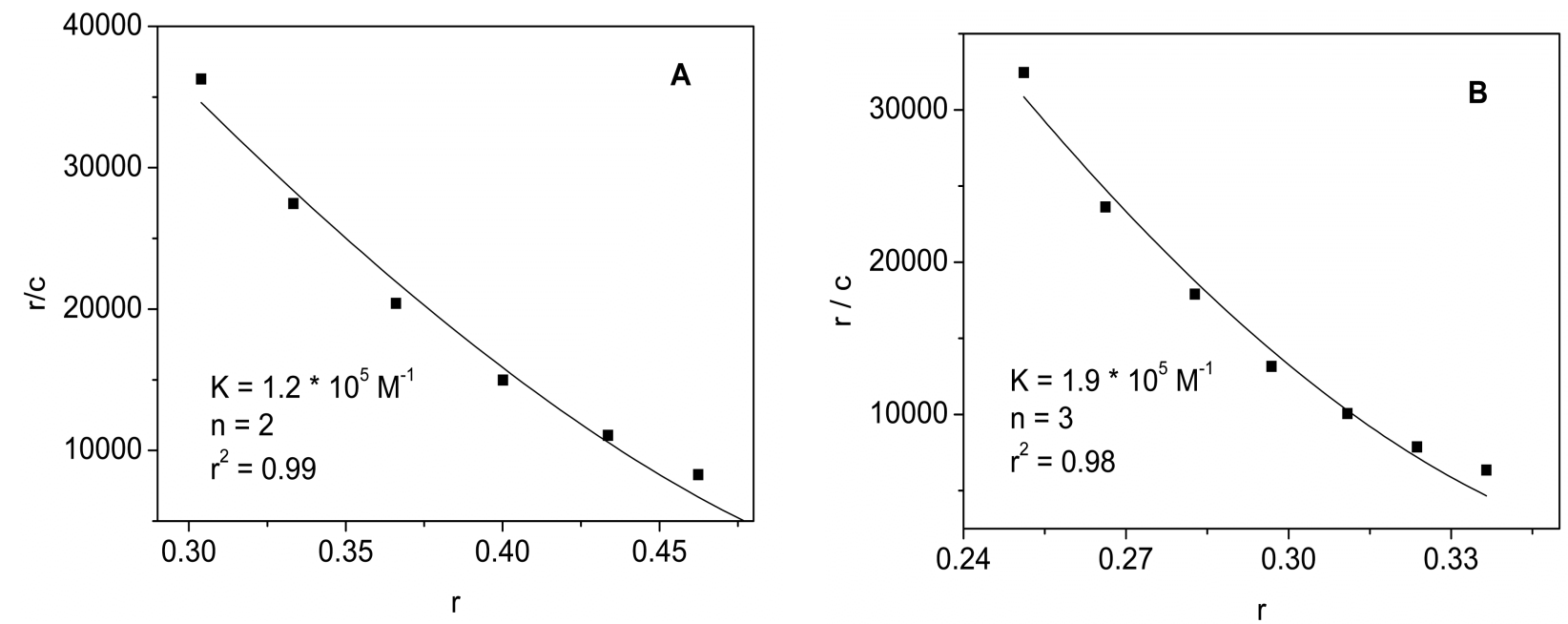

Figure S7. Scatchard plots derived from the spectrophotometric titration of ct DNA to dibenzoquinolizinium ions $\left[\mathbf{5 a}\left(\mathbf{B F}_{4}\right)\right](\mathrm{A})$ and $\mathbf{6}(\mathrm{B})$ in phosphate buffer $[10 \mathrm{mM}, \mathrm{pH} 7.0$, $T=25^{\circ} \mathrm{C} ; c($ quinolizinium $\left.)=10^{-4} \mathrm{M}\right]$.
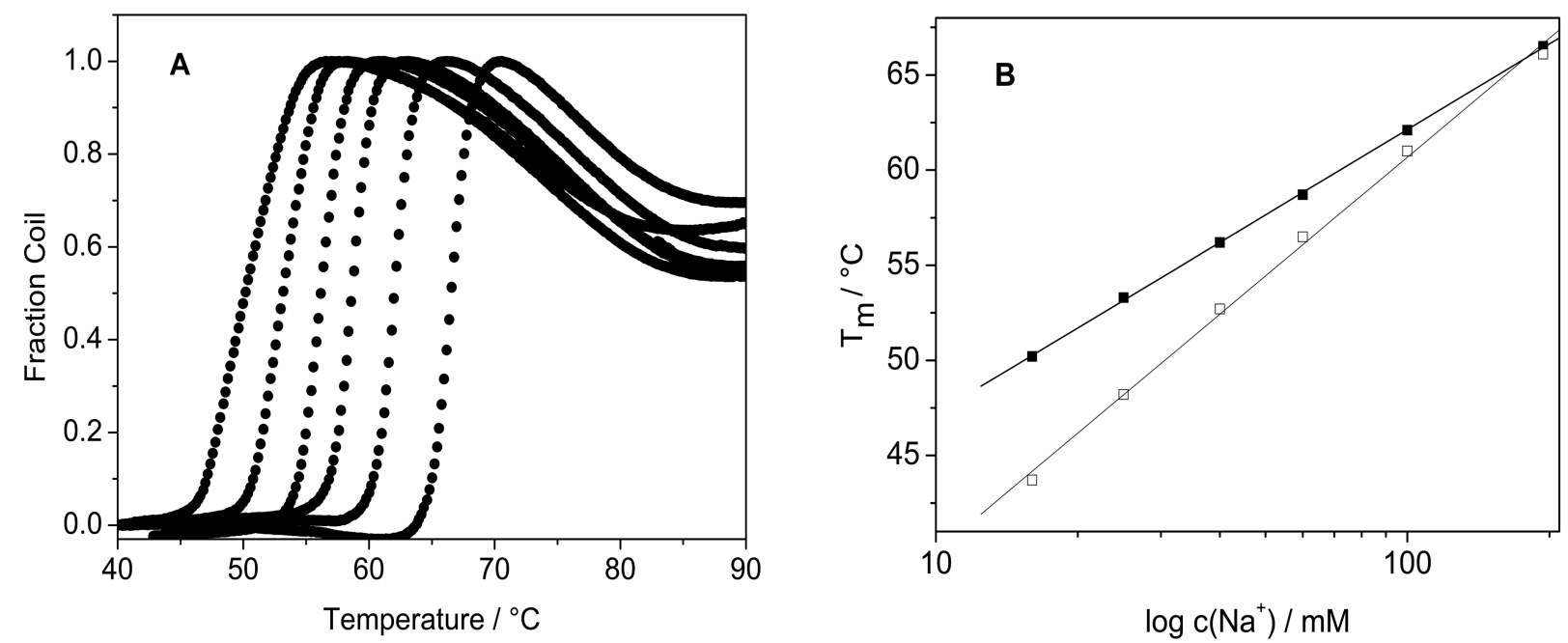

Figure S8. A: Melting profiles of poly[dA-dT]-poly[dA-dT] in the presence of dibenzo $[b, g]$ quinolizinium tetrafluoroborate $\left[\mathbf{5 a}\left(\mathbf{B F}_{4}\right)\right]$ at different $\mathrm{Na}^{+}$concentrations [from right to left: $16 \mathrm{mM}, 20 \mathrm{mM}, 40 \mathrm{mM}, 60 \mathrm{mM}, 100 \mathrm{mM}$ and $194 \mathrm{mM} ; c(\mathrm{DNA})=40 \mu \mathrm{M}$ (bt) in BPES buffer]. B: Dependence of $\mathrm{Na}^{+}$concentration on the DNA melting temperature of $\left[\mathbf{5 a}\left(\mathbf{B F}_{4}\right)\right]$ (filled squares) in comparison to DNA melting profiles in the absence of ligands (open squares). 


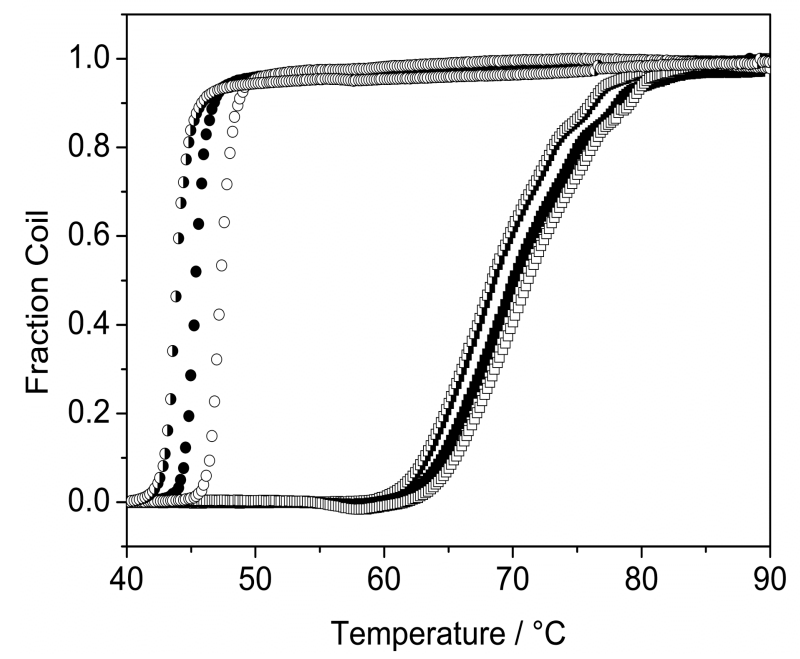

Figure S9. Melting profiles of poly[dA-dT]-poly[dA-dT] $(\bullet)$ and calf thymus DNA ( $\bullet$ ) in the presence of 9 at ligand-to-DNA ratios of 0 (half filled circles and squares), 0.2 (filled circles and squares), and 0.5 (open circles and squares); $c$ (DNA) $=40 \mu \mathrm{M}(\mathrm{bp})$ in BPE buffer.

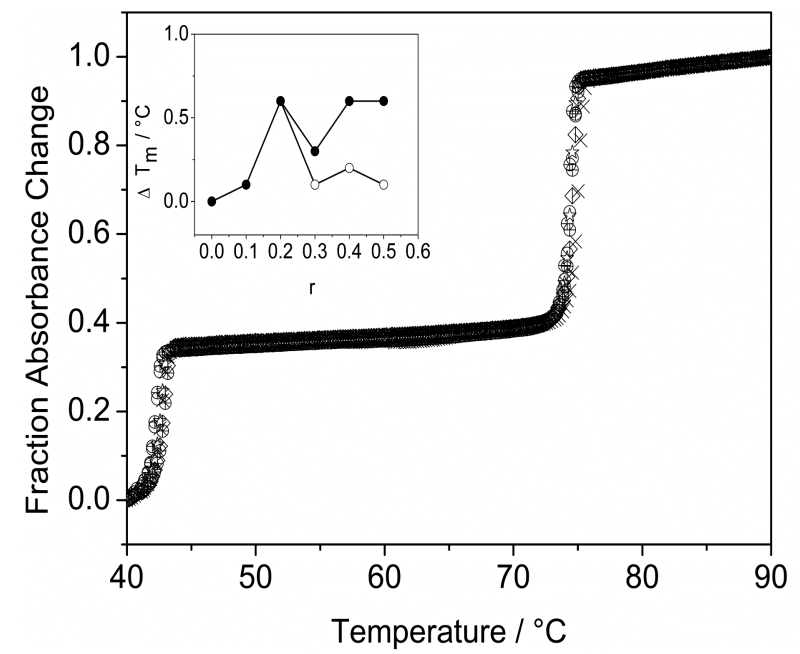

Figure S10. Melting profiles of poly $[\mathrm{dA}]-$ poly $[\mathrm{dT}]_{2}$ in the presence of $\mathbf{9}$ at ligand-to-DNA ratios $(r)$ of $0,0.1,0.2,0.3,0.4$ and $0.5 ; c(\mathrm{DNA})=40 \mu \mathrm{M}(\mathrm{bt})$ in BPES buffer. Inset shows the dependence of $T_{m}$ shifts ( $\Delta T_{m}{ }^{3 \rightarrow 2}$ : filled circles; $\Delta T_{m}{ }^{2 \rightarrow 1}$ : open circles) on the ligand-toDNA ratio. 


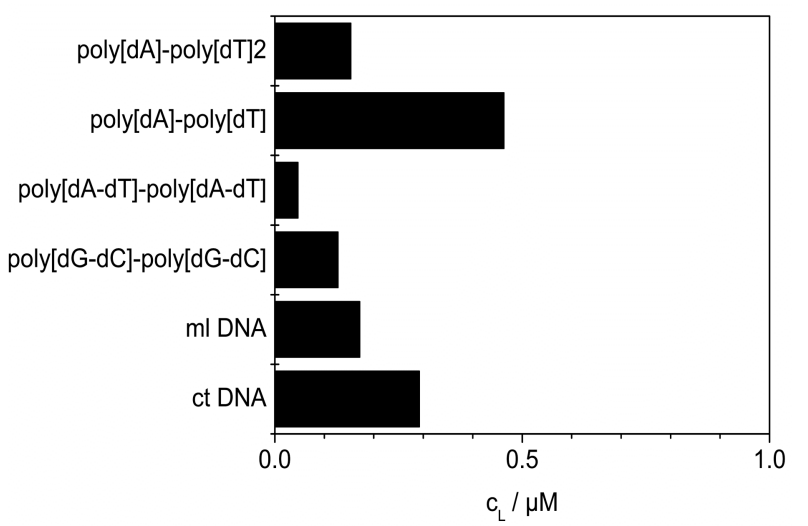

Figure S11. Competition-dialysis data for 9. Data are presented as bar graph in which the amount of ligand bound to each nucleic acid structure is plotted.

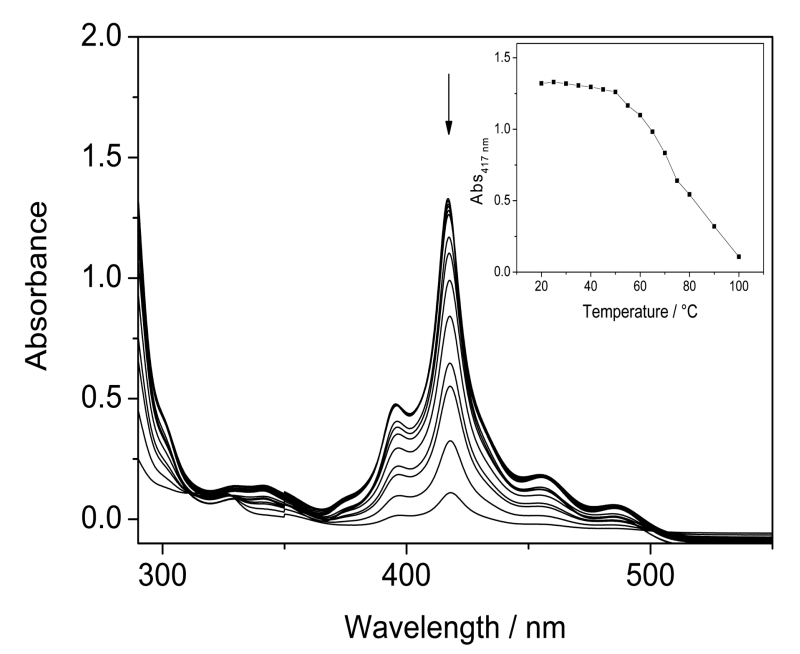

Figure S12. Thermal decomposition of $\mathbf{5 a}\left(\mathbf{B F}_{4}\right)\left(c=10^{-4} \mathrm{~mol} /\right)$ in BPES buffer as monitored by absorption spectroscopy at increasing temperature; $T=20-100{ }^{\circ} \mathrm{C}$. 


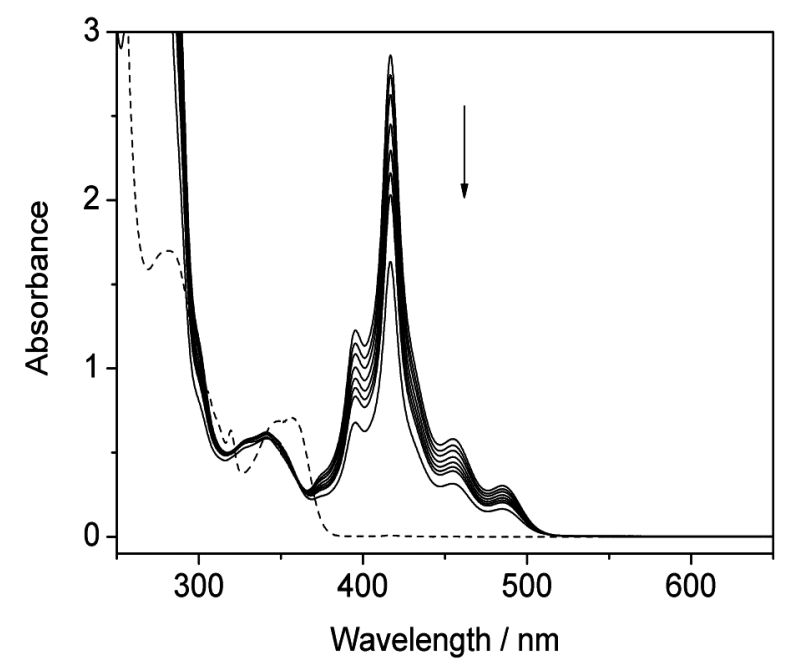

Figure S13. Decomposition of $\mathbf{5 a}(\mathbf{B r})$ (black line) in $\mathrm{H}_{2} \mathrm{O}$; the photometric detection was performed directly after irradiation of the dimer ahh-(5a) $)_{2}\left(c=1 \times 10^{-4} \mathrm{M}\right)$ and removal of 1 methoxynaphthalene; the arrow indicates the decrease of the monomer absorption; detection intervals: $4 \mathrm{~h}$ for $24 \mathrm{~h}$, then additional $12 \mathrm{~h}$, the sample was stored in the dark during the experiment.
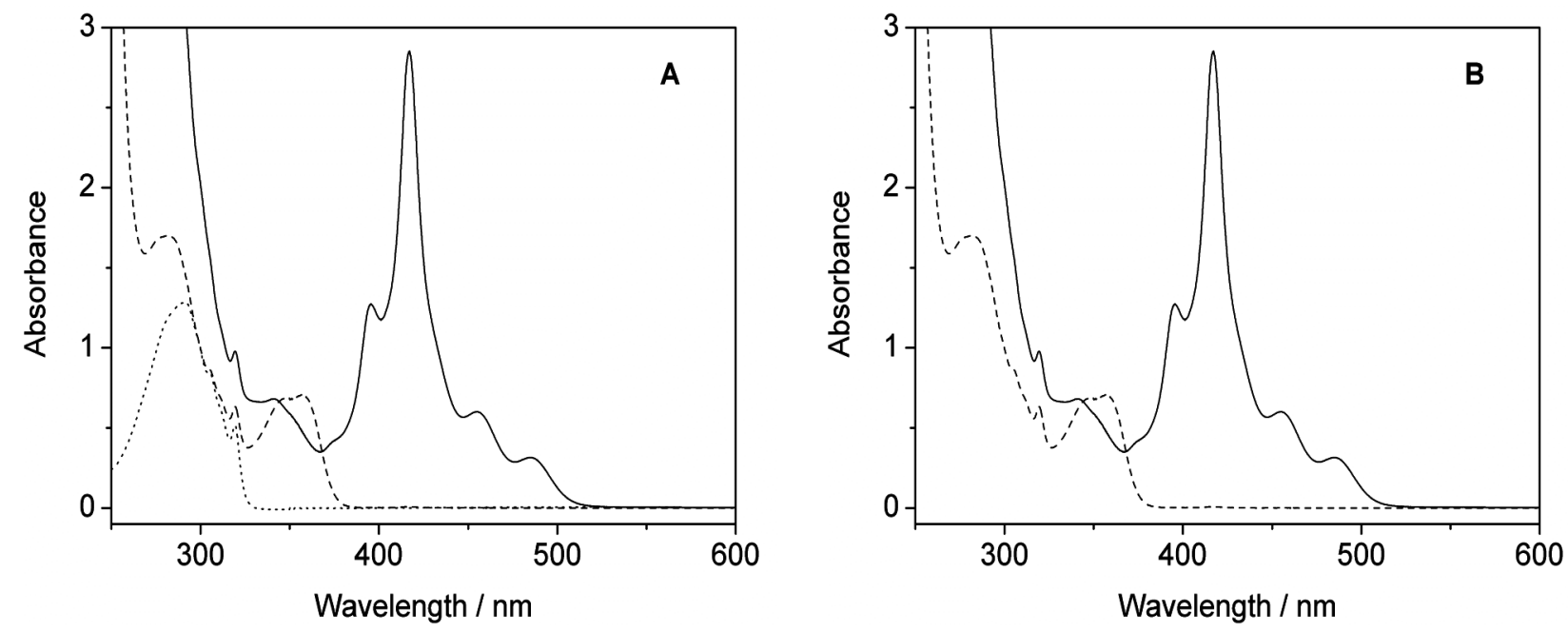

Figure S14. A: Absorption spectra of 1-methoxynaphthalene (dotted line, $c=2 \times 10^{-3} \mathrm{M}$ ), ahh-(5a) $)_{2}$ (dashed line; $c=1 \times 10^{-4} \mathrm{M}$ ), and $\mathbf{5 a}(\mathbf{B r})$ (solid line, $\left.c=2 \times 10^{-4} \mathrm{M}\right)$; $\mathbf{5 a}(\mathbf{B r})$ was obtained by irradiation ( $55 \mathrm{sec}, \lambda=350 \mathrm{~nm}$ ) of $\mathbf{a h h}-(\mathbf{5 a})_{2}$ in the presence of 1methoxynaphthalene in $\mathrm{H}_{2} \mathrm{O}$. B: Absorption spectra of $\mathbf{5 a}(\mathbf{B r})$ (solid line) that was obtained by irradiation of ahh-(5a) $)_{2}$ (dashed line; $c=1 \times 10^{-4} \mathrm{M}$ ) in the presence of 1 methoxynaphthalene $\left(c=2 \times 10^{-3} \mathrm{M}\right)$ in $\mathrm{H}_{2} \mathrm{O}$ through a cut-off-filter $(\lambda \geq 335 \mathrm{~nm})$. 

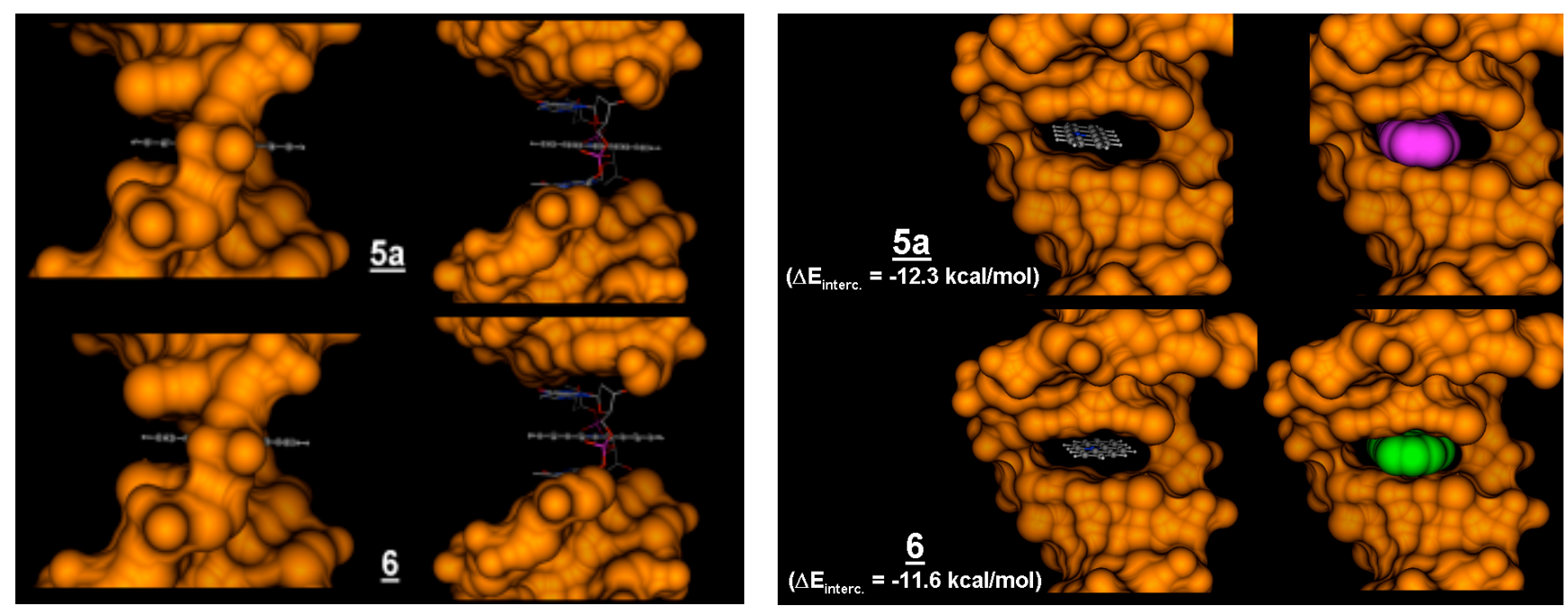

Figure S15. Optimized geometries of the intercalation complexes of dibenzoquinolizinium ions 5a and $\mathbf{6}$ with ds DNA as obtained by molecular docking simulations (see Experimental Section for details); ds DNA is represented by its Connolly's surface.

\section{References}

\footnotetext{
1 Fozard, A.; Bradsher, C.K. J. Org. Chem. 1966, 31, 3683.

2 Bradsher, C. K.; Beavers, L. E. J. Am. Chem. Soc. 1955, 77, 4812
} 